\title{
The advanced photonics laboratory at IIT-Madras
}

B. Gayathri, G. Venkat, A. Prabhakar

B. Gayathri, G. Venkat, A. Prabhakar, "The advanced photonics laboratory at IIT-Madras," Proc. SPIE 9793, Education and Training in Optics and

Photonics: ETOP 2015, 979322 (4 November 2015); doi: 10.1117/12.2223194

EPIE Event: Education and Training in Optics and Photonics: ETOP 2015, 2015, Bordeaux, France 


\title{
The Advanced Photonics Laboratory at IIT-Madras
}

\author{
Gayathri B. ${ }^{\mathrm{a}}$, G. Venkat ${ }^{\mathrm{a}}$ and A. Prabhakar ${ }^{\mathrm{a}}$ \\ ${ }^{a}$ Dept. of Electrical Engineering, Indian Institute of Technology Madras, Chennai, India.
}

\begin{abstract}
The advanced photonics laboratory is a biannual course offered to graduate students, after they have taken a few basic courses in optics and photonics. The course contents include experiments involving different areas in optics and photonics. Learning outcome includes theoretical formulation in optical phenomena and adoption of its instruments. Students are encouraged to explore experimental parameters, observe the effect on measured quantities, correlate them to theoretical predictions and finally explain any discrepancies. The methodology encourages students to question both theoretical models and experimental techniques.
\end{abstract}

\section{INTRODUCTION}

The Photonics group at the Indian Institute of Technology Madras offers several theoretical courses for students in the field of optics and photonics. The Advanced Photonics Laboratory was designed as a practicuum to add or supplement knowledge from the theory courses. The primary research areas of the photonics group in our institute are fiber lasers, optical sensors, non-linear optics, fiber optic communications and diffractive optics. In the Advanced Photonics Laboratory course, we offer various experiments to foster interest among young researchers to delve into each of the research areas. As part of the course, students are trained to use different equipment like digital storage oscilloscopes, optical spectrum analyzers, light wave measurement units, electrical spectrum analyzers etc. The experiments in this course are proposed by senior research scholars in the lab and are derived from their research areas. These senior students also act as mentors for their respective experiments and guide the participants of the course. Learning outcomes are specified for each experiment, and students are encouraged to relate their laboratory experience to the learning outcome.

\section{MODE OF CONDUCT OF COURSE AND EVALUATION}

The laboratory course is modeled as a practicum, where a student can enroll with a partial understanding of the theory. The course begins with an introductory class by the instructor, who gives the outline of all the experiments, how to interpret the results and explains the grading procedure. This course includes eleven different experiments, three to five hours per week, which broadly cover different areas of optics. Special invited lectures of faculty members working in different areas of optics are arranged before the laboratory sessions in order to provide the theoretical concepts behind an experiment. Teaching assistants schedule the experiment, circulate corresponding manuals to the students, book slots for instruments necessary for the experiment and intimate mentors and students about the preparedness of the experiment.

\subsection{Role of the mentor}

Each experiment is a part of research work carried out in our institute. Hence senior research scholars play a vital role as mentors to assist the student during the experiment. Students are expected to read the manual and appropriate references, in order to obtain a lucid idea about the experiment to be performed. Optical components and the equipments required for the specific experiment are demonstrated to the students along with the precautions and handling procedures. Mentors also conduct viva sessions, to ensure and evaluate the student's readiness in performing the experiment. The marks awarded for the viva also helps the instructor to understand the performance of the student. While performing the experiment, the mentor will assist the students as well as clarify their doubts, thus both get an opportunity to learn.

Education and Training in Optics and Photonics: ETOP 2015, edited by Eric Cormier, Laurent Sarger Proc. of SPIE Vol. 9793, 979322 · @ 2015 SPIE, IEEE, OSA, ICO · doi: 10.1117/12.2223194 


\subsection{Evaluation Methodology}

Students get their laboratory records evaluated by the mentors before next lab session. The instructor ensures that the interpretation of the results is adequate and appropriate. Online assignments are uploaded by instructor on the current trends in optics, typically related to an experiment, and providing students with exposure to popular research articles. The evaluation of APL is a three level assessment including two quizzes and an end semester examination. Quizzes are held as viva-voce conducted by the instructor after the students have performed a specific set of experiments. The written end semester examination of two hours duration consists of conceptual level questions to test their understanding in performing the experiments. At the end of the course, students are requested to fill up an online questionnaire in order to assess the learning outcomes they had acquired.

\section{DETAILS OF EXPERIMENTS}

A few important experiments performed in this laboratory course and their learning outcomes are presented in Table 1.

\begin{tabular}{|c|c|c|}
\hline Sl.No. & Name of the experiment & Objective and learning outcome \\
\hline 1 & $\begin{array}{l}\text { Construction and analysis } \\
\text { of a fiber ring laser }\end{array}$ & $\begin{array}{l}\text { Students design and study the characteristics of a } \\
\text { fiber ring laser. }\end{array}$ \\
\hline 2 & $\begin{array}{l}\text { Loss measurement of a } \\
\text { Silicon on Insulator (SOI) } \\
\text { waveguide }\end{array}$ & $\begin{array}{l}\text { Loss coefficient is estimated from Fabry Perot } \\
\text { resonance by coupling light into an SOI waveguide. } \\
\text { Students learn to align of free space optics. }\end{array}$ \\
\hline 3 & $\begin{array}{l}\text { Coherence length } \\
\text { measurement of a laser }\end{array}$ & $\begin{array}{l}\text { The coherence length and linewidth of a laser } \\
\text { source is measured using carrier suppressed active } \\
\text { homodyne method. Students also understand and } \\
\text { learn to use a Mach Zender Interferometer. }\end{array}$ \\
\hline 4 & $\begin{array}{l}\text { Fiber Bragg grating } \\
\text { (FBG) as a strain sensor }\end{array}$ & $\begin{array}{l}\text { The strain characteristics of an FBG sensor are } \\
\text { studied and the data is used to estimate the } \\
\text { unknown strain applied on a fiber in a test bed. }\end{array}$ \\
\hline 5 & $\begin{array}{l}\text { Optical diffraction and } \\
\text { it's utility }\end{array}$ & $\begin{array}{l}\text { The wavelength of a laser source is estimated using } \\
\text { principles of diffraction. Students are exposed to } \\
\text { error analysis techniques. }\end{array}$ \\
\hline 6 & $\begin{array}{l}\text { Four wave mixing } \\
\text { (FWM) non-linearity in } \\
\text { Kerr media }\end{array}$ & $\begin{array}{l}\text { Polarization dependence of conversion efficiency in } \\
\text { an FWM process is studied experimentally. }\end{array}$ \\
\hline 7 & $\begin{array}{l}\text { Temperature sensing } \\
\text { using Raman scattering }\end{array}$ & $\begin{array}{l}\text { Students are taught various scattering phenomena. } \\
\text { They observe the temperature dependence of Stokes } \\
\text { and anti-Stokes components in a Raman scattered } \\
\text { signal. }\end{array}$ \\
\hline 8 & LED transceiver circuit & $\begin{array}{l}\text { Students get a hands on experience in desiging their } \\
\text { own optical receiver board. }\end{array}$ \\
\hline
\end{tabular}

Table 1: Details of the experiments performed in Advanced Photonics Laboratory 


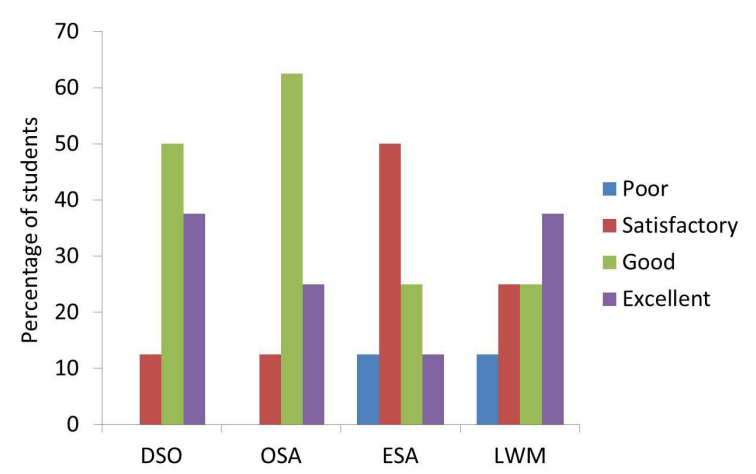

How well did you understand the importance of error analysis while data presentation?

Figure 1: Analysis of students response to (Left) : use of instruments. (Right) : importance of error analysis.

Apart from these experiments, students are also encouraged to learn data analysis techniques like fitting data to a theoretical model, distribution of residuals around the fit and identification of outliers [1]. The survey results in Fig. 1 show the ability of the students in using different instruments as well as applying error analysis on experimental data. As an example, we describe the fiber ring laser experiment in detail.

\subsection{Construction and analysis of a fiber ring laser}

One of the primary objectives of this experiment is to motivate students to experiment with the parameters of the laser cavity and gain an insight into the theoretical concepts of laser. The opportunity to work with a wide range of optical components makes it one of the vital experiments of this laboratory course. The fiber ring laser cavity includes $980 \mathrm{~nm}$ pump laser diode, WDM (1550/980 nm), Erbium doped fiber(EDF), couplers of different coupling ratios (50:50, 65:35 and 95:5) and isolators (980 and $1550 \mathrm{~nm}$ ). The characterization of each component performed before constructing the ring laser [2] ensures that students understand the significance of the specifications provided in the datasheet of an optical component. By changing the coupling ratios of the coupler in the cavity and observing the lasing spectrum, they understand how lasing depends on the gain-loss parameters. Fig. 2 shows the experimental setup as well as the L-I curve of a fiber ring laser for different output coupling ratios.
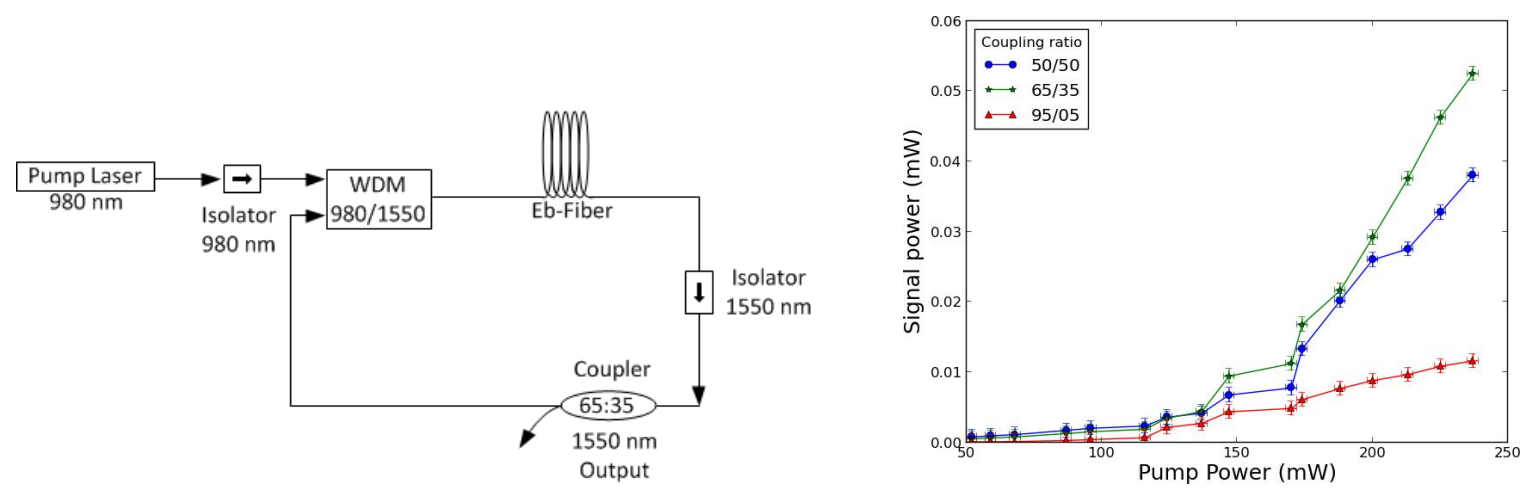

Figure 2: (Left) : A schematic of the setup of a fiber ring laser. (Right) : The L-I curve of the ring laser for different output coupling ratios.

Students understand the significance of selecting the length of the gain medium to eliminate any residual pump appearing at the output. The idea of selectivity in lasing wavelength is realized by incorporating a fiber Bragg grating in the cavity. The experiment also offers students to investigate various pumping schemes like backward and 
A

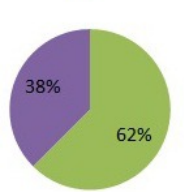

D

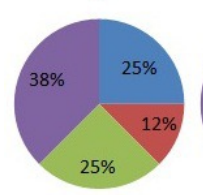

B

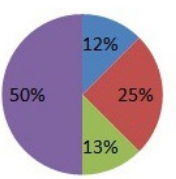

E

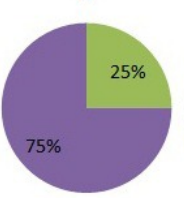

C

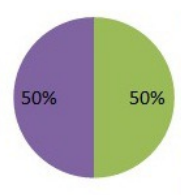

F

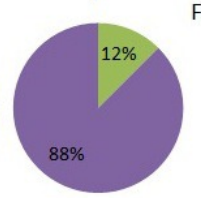

How well do you understand

A. The balance between gain and loss in the laser cavity

B. The source of noise in an optical amplifier

C. The influence of the pump power on the optical ASE spectrum

D. The effect of EDF length on the output power

E. The role of the different passive components used in a laser cavity

F. The role of FBG in choosing a lasing wavelength

apoor

- Satisfactory

m Good

- Excellent
How would you rate your confidence with designing laser and optical amplifier setups?

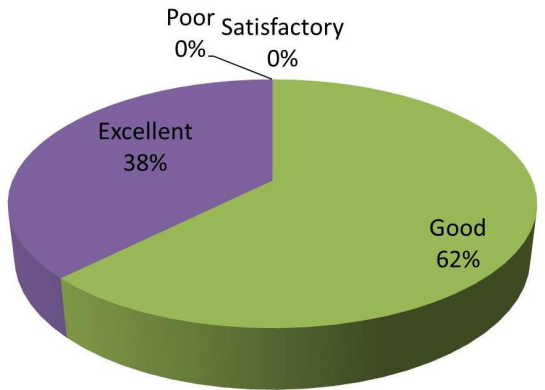

Figure 3: Analysis of student response to online questionnaire on fiber laser experiment

forward pumping. Students are provided with sufficient freedom for demonstrating their creativity in this experiment. By the end of this experiment the students are expected to demonstrate the balance between gain and loss in the laser cavity, the source of noise in an optical amplifier, the influence of the pump power on the optical ASE spectrum, the effect of EDF length on the output power and the role of the different passive components (WDM, coupler, etc) used in a laser cavity. The results of the survey are presented in Fig. 3. This experiment imparts sufficient amount of confidence in each participant to design laser and optical amplifier setups.

\section{CONCLUSION}

The Advanced Photonics Laboratory is a mandatory course for students aiming to use the experimental facilities of the photonics group. It provides students a hands - on experience with sophisticated instruments under the mentorship of senior students. The experiments depicted above are designed carefully to motivate the students towards design, analysis and interpretation. This lab enables scholars to deal with difficulties encountered and precautions to be taken while performing experiments and hence serves as a preparatory course for their research.

\section{ACKNOWLEDGEMENT}

We would like thank Arvind P. A., Gayathri M.S., Jyothish M., Kakarla Ravikiran, K Sai Krishna Reddy, Manas Srivastava, MD. Aftab Baig, Pabitro Ray, Parimal Sah, S. Bhargav, Srijith K., Sujith C. and Vaibhav Pratap Singh who were the mentors who contributed in designing the experiments. We would also like to thank some of the students of the course who contributed data for some of the plots in the paper.

\section{REFERENCES}

1. G. L. Squires "Practical Physics". Cambridge University Press, Aug-2001.

2. Silfvast W.T.,"Laser Fundamentals-Second Edition", Cambridge University Press, July-2008. 